\title{
Informed Consent Date
}

National Cancer Institute

\section{Source}

National Cancer Institute. Informed Consent Date. NCI Thesaurus. Code C93579.

The date (and time) the patient gives consent to a surgical or medical procedure or participation in a clinical study after achieving an understanding of the relevant medical facts and the risks involved. 